\title{
Falhas nos serviços de telefonia brasileira e o papel jurisdicional na tutela dos consumidores
}

As empresas que ofertam serviços de telefonia em território brasileiro acumulam ao longo do tempo uma gama de reclamações registradas periodicamente nos órgãos de proteção ao consumidor e, estão relacionadas principalmente ao funcionamento ou qualidade dos serviços prestados aos seus consumidores. Considerando estas informações, o presente trabalho tem por objetivo analisar, através do método dedutivo, dados relacionados ao histórico de falhas reiteradas na prestação de serviços de telefonia no Brasil e as estatísticas que demonstram o número de ações consumeristas buscando compreender a relação entre elas e o papel do controle jurisdicional para a proteção desses consumidores. Em seguida, a fim de entender os motivos pelos quais a tutela jurisdicional não consegue ser efetiva e pôr fim a esse processo de lesões reiteradas e acúmulo de processos, serão analisadas, por meio de estudo doutrinário e de legislações vigentes no país, as consequências da morosidade, da subutilização das ações coletivas e o baixo valor das indenizações por danos morais para o desempenho da tutela empregada, bem como o que pode ser feito para contornar essa situação. Diante das informações coletadas ao longo da pesquisa, conclui-se que, apesar da quantidade de ações consumeristas que envolvem as operadoras de serviços telefônicos do Brasil, a quantidade de clientes lesados continua em alta, dando a entender que, a tutela jurisdicional aplicada nessas relações de consumo não está sendo capaz de provocar desestímulos à prática de novas ofensas.

Palavras-chave: Lesões; Danos morais; Ações consumeristas; Morosidade; Punitive damages.

\section{Flaws in Brazilian telephone services and the jurisdictional role in consumer protection}

\begin{abstract}
Companies that offer telephony services in Brazil accumulate over time a range of complaints registered periodically in consumer protection agencies and are mainly related to the operation or quality of services provided to their consumers. Considering this information, the present work aims to analyze, through the deductive method, data related to the history of repeated failures in the provision of telephony services in Brazil and the statistics that demonstrate the number of consumeractions seeking to understand the relationship between them and the role of judicial control for the protection of these consumers. Then, in order to understand the reasons why judicial protection cannot be effective and put an end to this process of repeated injuries and accumulation of proceedings, the consequences of the slowness, underuse of class actions and the low value of compensation for moral damages for the performance of the guardianship employed will be analyzed by means of doctrinal study and legislation in force in the country, the consequences of the delay, the underuse of class actions and the low value of compensation for moral damages for the performance of the guardianship employed, as well as what can be done to get around this situation. Given the information collected throughout the research, it is concluded that, despite the amount of consumer ist actions involving telephone service operators in Brazil, the number of injured customers continues to rise, implying that the judicial protection applied in these consumer relations is not being able to cause disincentives to the practice of new offenses.
\end{abstract}

Keywords: Injuries; Moral damage; Consumerist actions; Lengthy; Punitive damages.

Topic: Direito do Consumidor

Reviewed anonymously in the process of blind peer.
Received: 20/05/2020

Approved: 18/08/2020
Mateus da Silva Dias

Universidade Federal do Tocantins, Brasil http://lattes.cnpq.br/8990091163210047 mateussdias06@gmail.com

Sérgio Augusto Pereira Lorentino (1)

Universidade Federal do Tocantins, Brasil http://lattes.cnpq.br/1559553649373663 http://orcid.org/0000-0001-9898-3305 sergiolorentino@uft.edu.br
Referencing this:

DIAS, M. S.; LORENTINO, S. A. P.. Falhas nos serviços de telefonia brasileira e o papel jurisdicional na tutela dos consumidores. Scientiam Juris, v.8, n.2, p.1-13, 2020. DOI: http://doi.org/10.6008/CBPC2318-3039.2020.002.0001 


\section{INTRODUÇÃO}

O número de falhas cometidas por empresas de telecomunicações não para de crescer e milhares de brasileiros são afetados todos os anos. Essas falhas são refletidas em reclamações aos órgãos de proteção dos consumidores. Por esse motivo, segundo dados do Sistema Nacional de Informações de Defesa do Consumidor (SINDEC, 2019), as empresas de telecomunicações ocupam as quatro primeiras posições dentre a mais demandas perante o Programa de Proteção e Defesa do Consumidor (PROCON).

O hábito de lesar seus clientes está enraizado na estrutura dessas companhias. Não obstante, ele gera danos patrimoniais e extrapatrimoniais provocando insatisfação e o surgimento de novas lides. Desta forma, também são expressivos os números de ações judiciais contra elas. Dados do Conselho Nacional de Justiça (CNJ, 2011) demonstram que as operadoras de telefonia ocupam o quarto lugar na lista dos maiores litigantes nacionais. Além disso, em outro estudo realizado em 2017, o CNJ afirmou que as telefônicas, juntamente com os bancos, são os mais demandados na justiça consumerista.

Entretanto, apesar da quantidade de ações movidas contra essas empresas o número de falhas não está diminuindo. Tal fato pode evidenciar a ineficácia da tutela jurisdicional para a proteção dos consumidores, uma vez que não está sendo capaz de gerar os desestímulos necessários para frear as condutas lesivas.

Assim, o tema abordado tem grande relevância social porque trata de falhas que lesaram milhares de consumidores, gerando problemas sociais como danos em massa e o abarrotamento do Poder Judiciário com ações consumeristas.

Nesta sistemática, este trabalho, utilizando-se do método dedutivo, irá analisar o histórico de falhas e reclamações registradas contra as empresas de telefonia brasileiras, a partir de dados divulgados pelo PROCON e pela ANATEL, bem com as estatísticas das ações consumeristas envolvendo as telefônicas objetivando demonstrar a reiteração sistemática de falhas e a falta de efetividade do Poder Judiciário em pôr fim a esse processo.

Em seguida, através de pesquisas bibliográficas, posicionamentos doutrinários e fundamentos legais, serão analisadas as hipóteses que giram em torno do tema para se chegar ao entendimento dos motivos que impedem a tutela jurisdicional de atingir resultados eficazes.

Serão verificadas as consequências da morosidade do judiciário na resolução da questão abordada, pois existe a possibilidade de que a demora na entrega de tutela esperada desestimule os consumidores a provocarem o Estado.

Também, será estudada a possível ineficácia da tutela individual em pôr fim às práticas lesivas, já que ela colabora para o inchaço e morosidade do Judiciário por causa da quantidade de ações para solucionar fatos semelhantes. Seguindo essa linha de raciocínio, também é importante investigar a subutilização das ações coletivas, pois seu uso pressupõe economia processual e celeridade do processo. Além disso, milhares de pessoas podem ser beneficiadas com uma única sentença favorável.

Por conseguinte, serão analisadas as indenizações por danos morais arbitradas nas ações envolvendo 
as operadoras de telefonia. Em regra, os valores baixos não são capazes de gerar impacto econômico suficiente para tornar o hábito de lesar economicamente inviável. Por isso cabe observar a possibilidade da utilização do instituto do punitive damages, que permite o arbitramento de indenizações grandes o suficiente para tornar a atividade lesiva economicamente inviável, desestimulando, assim, a reiteração de danos.

\section{DISCUSSÃO TEÓRICA}

\section{Das falhas na prestação dos serviços de telefonia}

Jorge Macedo (2015) retrata com maestria a situação do setor de telefonia brasileiro ao dizer que a falta de qualidade e a má prestação de serviços das operadoras brasileiras não é novidade para ninguém. Os consumidores enfrentam diariamente diversas perturbações, como cobranças indevidas, violação de contrato, vícios de serviço ou de produto, entre outros.

Nesse mesmo viés, Filgueiras (2016) relembra que em 2012 houve pane no setor e a Anatel teve que proibir a Claro, a OI e a TIM de comercializar novas linhas até que conseguissem fornecer serviço de qualidade.

Foi nesse cenário de falta de respeito e de compromisso com a qualidade que, ao longo dos anos, problemas técnicos generalizados e falhas contínuas, envolvendo essas e outras operadoras, geraram insatisfações em massa. Revoltados, eles buscaram resolver sua situação prestando queixas ao Programa de Proteção e Defesa do Consumidor (PROCON) ou à Agência Nacional de Telecomunicações (ANATEL).

Portanto, para esmiuçar os detalhes e a dimensão do problema abordado, faz-se necessário observar os dados a seguir que retratam o histórico de falhas e reclamações registrados nos últimos anos.

\section{Históricos de falhas e reclamações registradas pelo PROCON}

De acordo com o Sistema Nacional de Informações de Defesa do Consumidor (SINDEC), em 2019, as quatro primeiras posições dentre as empresas mais demandadas perante o PROCON foram ocupadas por empresas de telefonia. A OI FIXO/CELULAR, ficou em primeiro lugar com 166.181 reclamações, a VIVO/TELEFÔNICA/GVT com 155.210, a TIM/INTELIG com 127.394 e a CLARO/EMBRATEL/NET com 123.928. Destaca-se que o ano de 2019 é o que mais registrou reclamações desde 2004, ano do primeiro registro (SINDEC, 2019).

Podem-se verificar, na tabela abaixo, os tipos de reclamações dirigidas a essas quatro empresas juntas no ano de 2019.

Cobranças abusivas ou indevidas é o principal motivo pelo qual os consumidores acionaram o PROCON. O segundo motivo está relacionado com resolução de demandas, que engloba ausência de resposta, prolongamento exagerado de prazo e não suspensão imediata da cobrança. Já o terceiro envolve problemas no contrato, como rescisão, alteração unilateral, não cumprimento, transferências ou irregularidades. Vício e má qualidade do produto ou do serviço aparecem em quarto e acontece, por exemplo, quando o produto ou o serviço é mal executado, inadequado ou impróprio. 


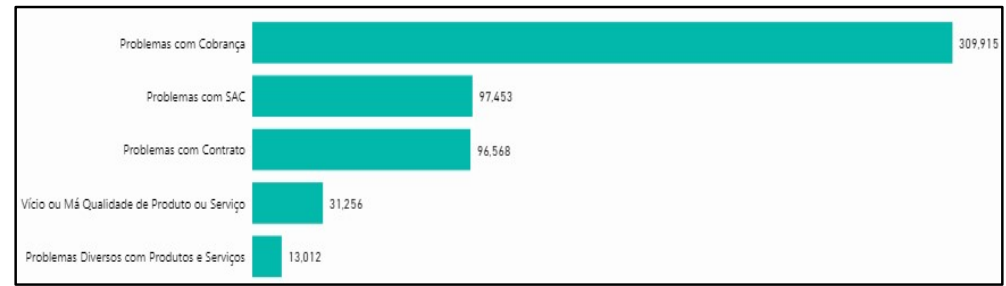

Figura 1: Principais problemas das empresas mais reclamadas em 2019. ${ }^{1}$

Já faz mais de dez anos que as telefônicas estão na mira dos consumidores. Mesmo assim, ainda não foram encontradas soluções para impedir o avanço das lesões. Dessa forma, os números de reclamações continuam crescendo.

Para evidenciar isso, nota-se que nos últimos 10 anos não houve mudanças significativas na prestação de serviços de telefonia celular no que tange a diminuição de reclamações, tendo em vista que o número delas contra as empresas telefônicas perante o PROCON em 2010 foi de 107,227, em 2011, 123,533, em 2012, 172,381, em 2013, 209,828, em 2014, 228,787, em 2015, 338,377, em 2016, 326,695, em 2017, 309,150, em 2018, 291,355, e em 2019, 353,783, sendo o ano com o maior número de registros dentre os outros. É importante destacar que, a partir do ano de 2015, a telefonia celular sempre esteve no topo dos assuntos mais reclamados (SINDEC, 2019).

A telefonia fixa, por sua vez, também sempre esteve entre os assuntos mais reclamados nos últimos 10 anos, em 2010, o número de reclamações foi de 86,999, em 2011, 86,096, em 2012, 125,584, em 2013, 207,828, em 2014, 228,454, em 2015, 241.163, em 2016, 191.609, em 2017, 187.027, em 2018, 168.640, e em 2019, 176.064 (SINDEC, 2019).

A pequena queda no número de reclamações a partir de 2016, neste caso, pode estar relacionada com a diminuição das linhas de telefonia fixa nos últimos anos. Até agosto de 2020, enquanto 227,3 milhões de brasileiros tinham acesso à telefonia móvel, apenas 30,9 milhões tinham acesso à telefonia fixa (ANATEL).

Para comparar a telefonia celular com a telefonia fixa, no que se refere aos dados das reclamações, bem como sua quantidade e os problemas que as motivam, deve-se observar as tabelas abaixo, ambas extraídas do site do SINDEC, que demonstram os dez problemas mais reclamados no ano de 2019.

Com relação ao motivo das reclamações, destaca-se que, na telefonia celular, no ano de 2019 , 158.639 reclamações foram motivadas por problemas com cobranças abusivas ou indevidas, correspondendo a $44,84 \%$ do total. Na telefonia fixa, o número foi de 76.818 (43,63\%). Essas porcentagens elevadas colocam as cobranças indevidas e abusivas como as principais causas das reclamações e insatisfação dos consumidores. Também fica nítido que a telefonia celular é responsável pela maioria das demandas ao PROCON (SINDEC, 2019).

${ }^{1}$ https://sindecnacional.mj.gov.br/report/Empresas. Acesso em: Outubro/2020. 


\begin{tabular}{|c|c|c|}
\hline Problema & Quantidade & $1 \%$ \\
\hline Cobrança indevida/abusiva & 158,639 & $44.84 \%$ \\
\hline $\begin{array}{l}\text { Dúvida sobre } \\
\text { cobrança/valor/reajuste/contrato/orçamento }\end{array}$ & 39,465 & $11.16 \%$ \\
\hline Contrato - Rescisão/alteração unilateral & 32,828 & $9.28 \%$ \\
\hline $\begin{array}{l}\text { SAC - Resolução de demandas (ausência de } \\
\text { resposta, excesso de prazo, não suspensão } \\
\text { imediata da cobrança) }\end{array}$ & 29,857 & $8.44 \%$ \\
\hline $\begin{array}{l}\text { SAC - Cancelamento de serviço (retenção, demora, } \\
\text { não envio do comprovante) }\end{array}$ & 13,115 & $3.71 \%$ \\
\hline $\begin{array}{l}\text { SAC - Acesso ao serviço (onerosidade, problemas } \\
\text { no menu, indisponibilidade, inacessibilidade aos } \\
\text { deficientes) }\end{array}$ & 11,889 & $3.36 \%$ \\
\hline $\begin{array}{l}\text { Serviço não fornecido (entrega/instalação/não } \\
\text { cumprimento da oferta/contrato) }\end{array}$ & 9,623 & $2.72 \%$ \\
\hline $\begin{array}{l}\text { Vício de qualidade (mal executado, inadequado, } \\
\text { impróprio) }\end{array}$ & 9,169 & $2.59 \%$ \\
\hline Venda/Oferta/publicidade enganosa & 4,608 & $1.30 \%$ \\
\hline $\begin{array}{l}\text { SAC - Acompanhamento de demandas (ausência } \\
\text { de registro numérico, não envio do } \\
\text { histórico/registro) }\end{array}$ & 4,514 & $1.28 \%$ \\
\hline
\end{tabular}

Figura 2: Telefonia Celular: os dez problemas mais reclamados em $2019 .^{2}$

\begin{tabular}{|c|c|c|}
\hline Problema & Quantidade & $\%$ \\
\hline Cobrança indevida/abusiva & 76,818 & $43.63 \%$ \\
\hline Contrato - Rescisão/alteração unilateral & 18,753 & $10.65 \%$ \\
\hline $\begin{array}{l}\text { Dúvida sobre } \\
\text { cobrança/valor/reajuste/contrato/orçamento }\end{array}$ & 17,585 & $9.99 \%$ \\
\hline $\begin{array}{l}\text { SAC - Resolução de demandas (ausência de } \\
\text { resposta, excesso de prazo, não suspensão } \\
\text { imediata da cobrança) }\end{array}$ & 15,159 & $8.61 \%$ \\
\hline $\begin{array}{l}\text { Serviço não fornecido (entrega/instalação/não } \\
\text { cumprimento da oferta/contrato) }\end{array}$ & 6,839 & $3.88 \%$ \\
\hline $\begin{array}{l}\text { SAC - Cancelamento de serviço (retenção, demora, } \\
\text { não envio do comprovante) }\end{array}$ & 6,536 & $3.71 \%$ \\
\hline $\begin{array}{l}\text { Vício de qualidade (mal executado, inadequado, } \\
\text { impróprio) }\end{array}$ & 5,445 & $3.09 \%$ \\
\hline $\begin{array}{l}\text { SAC - Acesso ao serviço (onerosidade, problemas } \\
\text { no menu, indisponibilidade, inacessibilidade aos } \\
\text { deficientes) }\end{array}$ & 4,758 & $2.70 \%$ \\
\hline Venda/Oferta/publicidade enganosa & 3,683 & $2.09 \%$ \\
\hline Recusa injustificada em prestar serviço & 2,769 & $1.57 \%$ \\
\hline
\end{tabular}

Figura 3: Telefonia Fixa: os dez problemas mais reclamados em $2019 .^{3}$

Outros problemas como dúvidas sobre cobranças e valores, ausência de resposta, não suspensão imediata de cobranças, excesso de prazo, rescisão ou alteração unilateral de contrato, dificuldades para cancelar serviços, indisponibilidade ou dificuldade para acessar os serviços contratados, vício de qualidade ou de produto, propaganda enganosa, não fornecimento do produto ou serviço, recusa em prestar serviço, cláusula abusiva no contrato, entre outros, representam uma parcela menor dentre os motivos que geram reclamações, mas evidenciam a diversidade de problemas arraigados à prestação de serviços de telefonia no Brasil (SINDEC, 2019).

\footnotetext{
${ }^{2}$ https://sindecnacional.mj.gov.br/report/Atendimentos. Acesso em: Outubro/2020.

${ }^{3}$ https://sindecnacional.mj.gov.br/report/Atendimentos. Acesso em: Outubro/2020.
} 
Históricos de falhas e reclamações registradas pela ANATEL

No que tange aos dados registrados pela à ANATEL (Agência Nacional de telecomunicações), houve uma leve queda nas reclamações dirigidas a ela entre os anos de 2015 a 2019. Na telefonia móvel, somando os dados referentes ao celular pós-pago e pré-pago, em 2015 foram registradas 1.821 .392 reclamações, em 2016, 1.855.637, em 2017, 1.629.931, em 2018, 1.334.097, e em 2019, 1.420.829, apresentando aumento, comparado ao ano anterior.

Dessa forma, apesar da queda de 2015 a 2018, em 2019 os números de reclamações voltaram a crescer. Em relação ao serviço de celular pós-pago, em 2019 foram feitas quase 70 mil reclamações a mais do que em 2018, totalizando um aumento de 7,2\%, chegando à marca de 1,04 milhão. Além disso, esse serviço foi o que apresentou mais queixas. A tabela abaixo demonstra o aumento que cada uma das operadoras teve separadamente.

\begin{tabular}{|c|c|c|c|c|c|c|c|}
\hline \multicolumn{2}{|c|}{ Prestadora } & 2015 & 2016 & 2017 & 2018 & 2019 & $2019-2018$ \\
\hline \multirow{2}{*}{ CLARO/NET } & Volume & 286.519 & 286.084 & 265.563 & 233.747 & 234.801 & $0,45 \%$ \\
\hline & Indice & 1,48 & 1,39 & 1,17 & 0,89 & 0,77 & $-0,12 p$ \\
\hline \multirow{2}{*}{ OI } & Volume & 185.616 & 180.840 & 152.189 & 125.584 & 139.251 & $10,88 \%$ \\
\hline & Indice & 1,72 & 1,67 & 1,38 & 1,08 & 1,01 & $-0,07 \mathrm{p}$ \\
\hline \multirow{2}{*}{ TIM } & Volume & 258.797 & 296.926 & 319.740 & 349.572 & 382.532 & $9,43 \%$ \\
\hline & Indice & 1,60 & 1,77 & 1,65 & 1,52 & 1,51 & $-0,01 \mathrm{p}$ \\
\hline \multirow{2}{*}{ VIVO } & Volume & 353.403 & 360.333 & 298.585 & 207.169 & 238.630 & $15,19 \%$ \\
\hline & Indice & 0,99 & 0,94 & 0,72 & 0,45 & 0,48 & $0,03 p$ \\
\hline
\end{tabular}

Figura 4: Volume e Índice de Reclamações (IR) do serviço de celular pós-pago por prestadora (2015-2019). Fonte: Sistemas Focus e Anatel Consumidor - SRC - Anatel.

Observa-se que, ao contrário das outras operadoras, a TIM vem piorando sua situação todos os anos. Porém, a VIVO, com 15,19\% e a OI com 10,88\% foram as que tiveram o maior aumento em 2019. Os principais motivos dessas reclamações foram queixas sobre cobrança ( $47 \%$ do total), principalmente no que diz respeito a diferenças nos valores cobrados.

\begin{tabular}{|c|c|c|c|c|c|c|c|}
\hline \multicolumn{2}{|c|}{ Prestadora } & 2015 & 2016 & 2017 & 2018 & 2019 & $2019-2018$ \\
\hline \multirow{2}{*}{ CLARO/NET } & Volume & 148.481 & 109.258 & 79.724 & 54.253 & 61.617 & $13,57 \%$ \\
\hline & Indice & 0,23 & 0,20 & 0,16 & 0,12 & 0,17 & $0,04 p$ \\
\hline \multirow{2}{*}{ OI } & Volume & 97.576 & 82.748 & 62.235 & 63.427 & 61.573 & $-2,92 \%$ \\
\hline & Indice & 0,20 & 0,18 & 0,16 & 0,18 & 0,20 & $0,01 \mathrm{p}$. \\
\hline \multirow{2}{*}{ TIM } & Volume & 223.723 & 266.676 & 244.952 & 213.675 & 180.270 & $-15,63 \%$ \\
\hline & Indice & 0,31 & 0,44 & 0,46 & 0,47 & 0,44 & $-0,03 p$ \\
\hline \multirow{2}{*}{ VIVO } & Volume & 123.163 & 135.325 & 97.200 & 66.775 & 68.520 & $2,61 \%$ \\
\hline & Indice & 0.20 & 0,27 & 0.21 & 0,15 & 0,18 & $0,02 p$ \\
\hline
\end{tabular}

Figura 5: Volume e Índice de Reclamações (IR) do serviço de celular pré-pago por prestadora (2015-2019). Fonte: Sistemas Focus e Anatel Consumidor - SRC - Anatel.

O serviço de Celular pré-pago contou com 377,3 mil reclamações em 2019. A tabela abaixo mostra que duas operadoras registraram crescimento em relação ao ano de 2018, a CLARO/NET teve 13,57\% e a VIVO de 2,61\% de aumento nas reclamações. Isso demonstra que o problema está longe de acabar, já que ainda está havendo pioras.

A questão mais reclamada nesse serviço está relacionada com o próprio crédito pré-pago (31\% do total). Além disso, motivos envolvendo cancelamento indevido registraram crescimento, principalmente na CLARO/NET. 
Para a telefonia Fixa, foram dirigidas à ANATEL, em 2015, 1.032 .448 reclamações, em 2016, 943.673, em 2017, 760.978, em 2018, 661.358, e em 2019, 595.147. Dentre os motivos que levam os consumidores a buscarem o auxílio da ANATEL, problemas com cobrança está em primeiro lugar, com $41 \%$ do volume total de demandas. Aqui a queda também pode estar relacionada com a diminuição das linhas de telefonia fixa no Brasil.

Em geral, problemas como cobranças não previstas no contrato e cobranças após o cancelamento são os assuntos mais recorrentes, assim como no PROCON.

A diminuição de reclamações de 2015 a 2018 registradas pela ANATEL pode ter dois significados. O primeiro é que os serviços de telefonia podem estar melhorando lentamente, mas em contrapartida os números voltaram a crescer em 2019. O segundo é que os consumidores podem estar perdendo a fé nesta agência e simplesmente deixando de registrar suas reclamações ali para buscar solução em outro mecanismo de proteção.

Nesse sentido, as reclamações registradas pelo PROCON, apesar de ter tido quedas entre os anos de 2016 a 2018, também cresceu e teve seu recorde no ano de 2019, superando os números de 2015 (SINDEC, 2019). Além disso, as telefônicas gradualmente se tornaram os maiores alvos de ações consumeristas no Brasil.

O fato é que os números ainda são grandes e refletem um funcionamento inadequado do setor de telefonia e uma possível ineficácia das medidas tomadas pelos mecanismos de proteção e fiscalização, sobretudo, pelo poder judiciário.

\section{Estatística das ações consumeristas envolvendo as Telefônicas}

Apesar de algumas queixas serem solucionadas com a intermediação do PROCON, da ANATEL ou diretamente com a empresa, boa parte das demandas provenientes de lesões praticadas por telefônicas vão parar no judiciário. O número de ações é significante e expressa à gravidade do problema inerente a prestação de serviços de telefonia no Brasil.

Segundo o Conselho Nacional de Justiça (CNJ, 2011), as operadoras de telefonia, juntas, ocupam a quarta posição na lista dos 100 maiores litigantes do Brasil. Além disso, em outro estudo realizado entre os anos de 2017, o CNJ afirmou que elas, juntamente com os bancos, são os mais demandados na justiça consumerista.

Este último estudo foi encomendado pelo CNJ à Associação Brasileira de Jurimetria e analisou dados de sete Tribunais de Justiça da federação: TJAM, TJSP, TJBA, TJDFT, TJMT, TJRJ, TJRS. Constatou-se que 40\% dos processos consumeristas existentes nessas unidades têm como alvo empresas de telefonia ou instituições financeiras. Desses litígios, a maioria envolve indenizações por danos morais, ocasionados pela inscrição injusta no cadastro de inadimplentes.

Dentre todos os tribunais analisados o setor de telecomunicações sempre consta entre os três maiores litigantes em ações consumeristas, ficando em primeiro no TJRJ, com 574.943 ações, e no TJDFT, com 13.251. Também está em segunda posição no TJMT, com 39.941 ações, no TJRS, com 246.293, e no TJSP 
com 152.812.

Considerando os processados de forma individualizada, a Ol está entre os cinco maiores litigantes consumerista em quatro dos sete tribunais analisados, ficando em primeiro no TJRJ, com 226.062 ações ( $12,8 \%$ do total) e no TJRS, com 142.900 ( $13 \%$ do total). A operadora CLARO aparece em destaque no TJDFT, TJMT e TJRJ, somando 125.351 processos. Outra que se destaca é a VIVO, estando entre os maiores litigantes no TJMT, TJDFT e no TJSP, contabilizando 73.491 ações.

Cabe ressaltar que os dados dessa pesquisa evidenciam que além das empresas de telecomunicações estarem entre os maiores litigantes do Brasil, de modo geral, também estão entre os mais demandados na justiça consumerista.

\section{Da possível ineficácia da tutela jurisdicional aplicada nas ações consumeristas}

Relacionando os dados do SINDEC e da ANATEL com os do CNJ, verifica-as dois importantes pontos: o primeiro é que o número de reclamações contra as telefônicas está crescendo e o segundo é que elas estão entre os maiores litigantes da justiça consumeristas.

Mas, apesar da grande quantidade de demandas ao judiciário, o número de reclamações não apresentou quedas significativas nos últimos anos. No PROCON, mesmo com uma leve diminuição entre os anos de 2016 a 2018, em 2019 foram registradas a maior quantidade de reclamações dos últimos dez anos. Na ANATEL não foi diferente, os números voltaram a crescer em 2019.

Hasse (2013) ensina que ao buscar a tutela jurisdicional, o indivíduo visa satisfazer ou cessar ameaça ao seu direito. Assim, espera-se que o Estado empregue uma tutela efetiva e eficaz, sendo aquela que produz efeitos satisfatórios no mundo fático, atingindo os objetivos ora almejados.

Quando o que se espera é colocar fim ao problema social causado por lesões em massa, a tutela jurisdicional aplicada no caso em questão não está sendo eficaz, pois não é capaz de gerar desestímulos à reiteração de falhas e lesões praticadas pelas operadoras de telefonia. Além disso, não está conseguindo evitar o abarrotamento do judiciário devido o ajuizamento de ações em massa.

\section{Do controle jurisdicional para a tutela dos consumidores de serviços telefônicos}

O Estado, através do Poder Judiciário, tem o dever e o poder para frear as condutas lesivas e combater a reiteração de falhas por parte dos fornecedores. Cavalieri Filho (2019) explica que o constituinte originário de 88 consagrou a defesa ao consumidor como uma obrigação constitucional do Estado, sendo enquadrado no rol de direitos fundamentais. Deste modo, o consumidor que antes não tinha seus direitos reconhecidos, passou a ser amparado por um direito fundamental. O direito à defesa do consumidor está gravado no art. $5^{\circ}$, inciso XXXII e ADCT 48, ambos da CRFB/88.

Filomeno ressalta a dimensão da importância que o constituinte deu a defesa do consumidor ao incluí-lo, no art. 170, inciso V, da CRFB/88, como um dos princípios da ordem econômica.

O direito à proteção do Estado também é reconhecido no artigo $4^{\circ}$, inciso II, alínea " $\mathrm{c}$ " da Lei 8.078, de 11 de setembro de 1990, conhecida como o Código de Defesa do Consumidor - CDC. Não obstante, o art. 
$5^{\circ}$ do mesmo diploma legal também afirma a imprescindibilidade da tutela jurisdicional para a efetivação dessa proteção.

Dito isso, fica claro a importância e o papel do poder judiciário no combate à reiteração de falhas e lesões das operadoras de telefonia, uma vez que isso é fundamental para a proteção e segurança dos consumidores de serviços telefônicos. Faz-se necessário, então, estudar o modo como esse controle jurisdicional pode ser exercido, os fatores que impedem o judiciário de conseguir cumprir com tal objetivo e o que poderia ser feito para contornar a situação relatada nos títulos anteriores.

\section{Demora na entrega da tutela jurisdicional}

A morosidade é um problema sério que atinge o Poder Judiciário brasileiro há muito tempo. Tamanha é a sua gravidade que para tentar solucioná-lo foi necessário recorrer ao elevado nível constitucional, com a confecção da emenda número 45 de 2004 (MENDES, 2012). Com ela, a Constituição Federal de 1988 passou a assegurar a todos, em seu artigo $5^{\circ}$, inciso LXXVIII, o direito à razoável duração do processo e aos meios que garantam a celeridade em sua tramitação, seja no âmbito judicial ou administrativo. No entanto, isso está longe de ser a realidade do Brasil.

Bodas (2017), explica que o judiciário brasileiro é o $30^{\circ}$ mais lento dentre os 133 analisados pelo Banco Mundial. Não obstante, a demora na resolução das demandas, segundo o CNJ, gera um acúmulo excessivo de processos. Por consequência, Teófilo (2020) ressalta que o ano de 2019 finalizou com 77,1 milhões de processos que ainda não tiveram solução definitiva. Logo, além de estar abarrotada de ações, a justiça brasileira não consegue entregar a tutela jurisdicional de forma célere.

Essa lentidão se dá porque os agentes do poder judiciário não conseguem absorver os feitos destinados à sua apreciação, assim como os tribunais, que não se mostram capazes de se desincumbir do crescimento e acúmulo de processos (GIANULO, 2015). Os motivos que justificam essa lentidão podem estar relacionados a diversos fatores, como complexidade das causas, comportamento das partes, atuação do judiciário, volume demasiado de processos, entre outros.

Cesconetto (2020) enfatiza que, a morosidade processual e a burocracia desanimam muitas pessoas a discutirem seus direitos na Justiça. Para ela, a demora coloca o cidadão em um estado de descrença no poder judiciário. É justamente por esse motivo que Mendes (2012) ensina que ela também prejudica o acesso à justiça, no sentido de que, muitas vezes, não entrega a tempo o direito almejado.

Sobre o prejuízo que a morosidade traz para efetividade do processo consumerista, Miragem ensina que:

Uma das preocupações mais candentes em matéria de tutela de direitos é o da efetividade do processo. Isto porque, segundo a experiência prática amplamente reconhecida, a morosidade processual, e sua projeção excessiva no tempo, assim como a ausência de uma resposta prática adequada para o lesado que busca no Poder Judiciário a proteção legítima de seus interesses, vêm em prejuízo dos menos favorecidos, que não possuem condições, seja de arcar com os custos da demanda por período tão grande, ou com a tibieza de seu resultado prático, assim como serve de estímulo ao ofensor do direito que é demandado, à repetição da conduta antijurídica. (MIRAGEM, B. 2016) 
Assim, fica claro que a demora na entrega da tutela também é um dos fatores que motivam a reiteração das condutas lesivas, uma vez que, a fragilidade econômica do consumidor em relação às empresas ofensoras impede a manutenção da igualdade na relação processual quando o processo perdura excessivamente, permitindo que o ofensor não sofra as devidas consequências de suas ações antijurídicas.

Por conseguinte, a morosidade desestimula muitos consumidores fazendo com que eles deixem de provocar a jurisdição. Por esse motivo a quantidade de lesões e reclamações crescem constantemente de modo que os números de soluções dadas pela justiça não conseguem acompanhar esse crescimento.

\section{Ineficácia das ações individuais e a subutilização das ações coletivas}

Um dos problemas que colaboram para a baixa efetividade da tutela jurisdicional, para o crescimento das ações e, por consequência, para a demora na entrega da tutela esperada, é a grande quantidade de ações individuais ajuizadas para tratar de demandas semelhantes que poderiam ser discutidas em uma única ação coletiva.

Por isso o artigo 81 do Código de Defesa do Consumidor, consagrou o uso das ações coletivas para a defesa de direitos e interesses difusos, dito aqueles transindividuais, de natureza indivisível, dos quais são titulares pessoas indeterminadas ligadas por uma situação de fato; coletivos, também transindividuais e indivisíveis, mas que o seu titular faça parte de grupo, classe ou categoria de pessoas ligadas entre si ou com a parte oposta; e individuais homogêneos, que são aqueles que nascem de origem comum. A violação desses direitos é corriqueira nas relações de consumo, sobretudo no fornecimento de serviços de telefonia.

É, portanto, notória a importância dos processos coletivos para a resolução de conflitos consumeristas inerentes a uma sociedade de massa, sobretudo por ter como características um menor custo e duração razoável. Com esse modelo de ação o poder judiciário pode resolver mega conflitos de forma isonômica evitando que eles sejam fracionados em várias ações individuais (MIRAGEM, 2016).

Segundo o Instituto de Defesa coletiva, as ações coletivas de consumo reúnem vários agentes em uma mesma ação. Dessa forma, vários consumidores podem ser beneficiados por uma única sentença que terá efeito erga omnes ou ultra partes.

Porém, pesar de ser um direito positivado e trazer uma série de benefícios para os consumidores, Gasparin (2019) afirma que as ações coletivas ainda não são muito utilizadas no Brasil. Atualmente, o Poder Judiciário conta com aproximadamente 77,1 milhões de processos, porém, o Brasil registrava até o ano de 2017, apenas 62,210 ações coletivas em andamento.

De acordo com CNJ, há dois fatores que faz com que as partes optem pelas ações individuais em detrimento das ações coletivas. O primeiro é que os tribunais possuem jurisprudências que permitem a flexibilidade da aplicação da coisa julgada das ações coletivas às ações individuais. Segundo, os tribunais permitem o ajuizamento de ações individuais mesmo na hipótese das coletivas terem obtido sentença procedente, ou seja, fica a critério da parte escolher se vincular ou não a uma ação coletiva. Dessa forma, $\mathrm{O}$ CNJ afirma que, nessas condições, o cenário atual é de proliferação de ações individuais.

Não obstante, a escolha por ações individuais quando se há a possibilidade de usar as ações coletivas 
vai de encontro aos princípios da celeridade, razoável duração do processo e economia processual, uma vez que a quantidade demasiada de demandas individuais abarrota o judiciário, o tornam lento e prejudicam a efetividade de sua tutela, permitindo, assim, a fragilização dos consumidores e o crescimento de lesões e processos.

\section{Baixo valor das indenizações por danos morais e a possível aplicação do Punitive Damages}

A melhor definição para danos morais, segundo Tartuce (2016), seria simplesmente a lesão aos direitos de personalidade. Segundo ele, sua reparação não visa quantificar o sofrimento ou a dor de alguém, mas servir como um paliativo para os danos extrapatrimoniais.

Para Nunes (2018), existem alguns parâmetros importantes para a fixação da indenização pecuniária por danos morais, quais sejam: a existência de má-fé do ofensor ou o grau da sua culpa, a capacidade econômica do ofensor, a possibilidade ou capacidade do ofensor de voltar a causar o mesmo dano, se o ofensor já havia cometido aquela falta antes, a necessidade de punir, entre outros.

Nas relações consumeristas, a hipótese de incidência do dano moral está prevista no art. $6^{\circ}$, inciso VI, do CDC e sua aplicação está vinculada ao princípio do não enriquecimento sem causa. Segundo Flávio Tartuce (2016), o direito brasileiro não admite qualquer conduta que resulte no enriquecimento sem razão, pois o Código Civil de 2002 valoriza o trabalhador e não o que fica esperando por um golpe de mestre para se enriquecer à custa do outro.

Assim, o que se observa no Brasil é a aplicação de indenizações baixas por danos morais independentes do poder econômico do ofensor e de seu potencial para reincidir.

No que tange às operadoras de telefonia, Cardoso (2019) foi enfático ao dizer que elas zombam dos consumidores, ganhando cada vez mais e persistindo em suas práticas imorais e, muitas vezes, ilegais. Essa falta de respeito à lei e às decisões advém do fato de que sabem que as indenizações são baixas e, no fim, as multas diárias serão revogadas, porque para a maioria dos julgadores isso caracteriza enriquecimento ilícito.

Sobre esse ponto de vista, Duque declara que as indenizações por danos morais pífias aplicadas nas ações consumeristas não conseguem superar o lucro que as operadoras de telefonia têm com a continuidade das ações lesivas, tal fato faz com que seja economicamente vantajosa a prestação defeituosa dos serviços.

Na visão de Cardoso (2019), como consequência do cenário descrito acima, "o consumidor acuado acaba sendo desestimulado pelo poder que mais deveria protegê-lo: o Judiciário".

Para contornar essa situação, o Poder Judiciário poderia adotar o instituto do punitive damages, que pode ser traduzido como danos punitivos, sendo um instituto jurídico adotado pelos Estados Unidos da América - EUA que segue a vertente da função punitiva dos danos morais. Assim, ele permite que os juízes norte-americanos apliquem punições severas aos transgressores, desestimulando-o a reincidência dos danos. Este instituto também é conhecido como teoria do desestímulo (FURLANETTO, 2013).

Galli (2017) destaca que o punitive damages possui cinco funções essenciais: fazer justiça incentivando o infrator a cumprir a lei; prevenir ou impedir que novos delitos sejam cometidos; punir o ofensor; educar tanto o causador do dano quanto ao ofensor em potencial; e, por último, a função vingativa, 
que visa evitar que o ofendido cometa ato ilícito para se vingar daquele que o ofendeu.

Com base nisso, Furlanetto (2013) explica que, para aqueles que adotam a Teoria do Desestímulo, não basta apena a aplicação da função compensatória dos danos morais, também é indispensável à aplicação de suas funções punitiva e pedagógica. Desde modo, o valor arbitrado poderá atenuar a dor resultante da lesão e, ainda, ser capaz de atingir o patrimônio do lesante o suficiente para puni-lo e, ao mesmo tempo, servir de exemplo para toda a sociedade, evitando, assim, a repetição do ocorrido.

Também coaduna deste pensamento o doutrinador Bittar (2015). Segundo ele os danos morais devem ser arbitrados não só para diminuir os sofrimentos causados pelos danos, mas também impor ao lesante o peso de sua conduta negativa, objetivando a manutenção da ordem e da tranquilidade social.

Lima critica o fato de que, nos EUA, o punitive damages possibilitou a formação de uma verdadeira indústria da indenização. Portanto, o nosso país, para adotar esse instituto, teria que combater isso e tomar cuidado para que, por falta de preparo do julgador, não sejam arbitrados valores exorbitantes (2009).

O que se busca com essa teoria não é a simples aplicação de indenizações milionárias, como é comum nos EUA, mas sim provocar uma transformação no judiciário brasileiro para obter a estipulação de valores mais justos nas indenizações por danos morais (LIMA, 2009).

O direito brasileiro não pode mais permitir que as relações de consumo permaneçam entremeadas de falhas e má prestação dos serviços. As telefônicas estão há anos cometendo as mesmas infrações. Elas são especialistas em lesar seus clientes e são melhores ainda em não cessar essas lesões. A adoção da teoria do desestímulo, seria de grande importância no processo para educar essas empresas fazendo com que elas não voltem a agir assim.

\section{CONCLUSÕES}

As telefônicas estão entre os maiores demandados perante o PROCON, além de serem alvos de milhões de reclamações registradas por ano na ANATEL. Nos últimos dez anos elas têm lesado seus clientes corriqueiramente de modo que o número de ofensas apresentou crescimento em vários anos consecutivos.

Elas também são uma das maiores litigantes do Brasil. No entanto, apesar da grande quantidade de ações consumerista envolvendo operadoras de telefonia, o número de lesões e reclamações contra elas não estão caindo. Conclui-se, portanto, que a tutela jurisdicional aplicada nessas relações de consumo não está sendo capaz de provocar desestímulos à prática de novas ofensas.

A falta de efetividade do judiciário, nesse caso, pode ser associada a alguns fatores tais como a demora na entrega da tutela jurisdicional. É fato que o judiciário brasileiro é um dos mais lentos do mundo. A morosidade desestimula os lesados a procurarem a justiça, limita o acesso à justiça, prejudica os consumidores menos favorecidos que não conseguem manter os custos de uma ação por muito tempo. Tudo isso reduz a efetividade da tutela e colabora para a continuidade das lesões.

Uma das formas para amenizar a morosidade e a reiteração de falhas seria a utilização de ações coletivas na proteção dos consumidores. Elas são pautadas nos princípios da celeridade, da razoável duração do processo e da economia processual, pois englobam vários agentes na mesma ação e pode beneficiá-los 
com uma única sentença favorável. Dessa forma, têm o condão de evitar a multiplicação exagerada de ações individuais e com isso impedir o congestionamento do judiciário e a sua falta de efetividade.

Outro aspecto que dificulta elaboração de uma tutela eficaz para proteção dos consumidores de serviços telefônicos é que o valor arbitrado nas indenizações por danos morais é irrisório se comparadas ao poder econômico dos ofensores. Nesse caso, o Judiciário poderia adotar a teoria do desestímulo, passando a considerar a aplicação do caráter punitivo-pedagógico dos danos morais. Dessa forma, seria possível a estipulação de valores grandes o suficiente para que lesar os clientes deixasse de ser vantajoso, provocando o desestímulo necessário para que deixem de provocar novas ofensas.

\section{REFERÊNCIAS}

BITTAR, C. A.. Reparação por danos morais. São Paulo: Saraiva, 2015.

BODAS, A.. Por que a Justiça brasileira é lenta?. 2017.

BRASIL. Planalto Federal. Constituição da República Federativa do Brasil. Brasília: DOU, 1988.

BRASIL. Planalto Federal. Lei 8.078: Código de Defesa do Consumidor. Brasília: DOU, 1970.

CARDOSO, G. T.. O retrocesso da quantificação dos danos morais nos dias atuais: $A$ quem interessa. Cuiabá: $O A B$ Matogrosso, 2019.

CAVALIERI FILHO, S.. Programa de direito do consumidor. 5 ed. - São Paulo: Atlas, 2019.

CESCONETTO, G.. Morosidade Processual: por que a tramitação dos processos demora tanto?. 2020.

DUQUE, B. L.. Indenização com caráter pedagógico: O caso da má prestação de serviços de telefonia. 2015.

FILGUEIRAS, M. L.. Como a telefonia mudou para que tudo ficasse como está. 2016.

FILOMENO, J. G. B.. Direitos do consumidor. São Paulo: Atlas, 2018.

FURLANETTO, D.. Novos paradigmas da responsabilidade civil: a (im)possibilidade da aplicação da teoria do desestímulo. Santa Maria: UFSM, 2013.

GALLI, C. R.. A utilização dos punitive damages no Direito brasileiro à luz do Código de Defesa do Consumidor.
Palmas, 2017.

GASPARIN, M.. Ações coletivas ainda são pouco utilizadas pelos brasileiros. 2019.

GIANULO, W.. A demora na entrega da tutela jurisdicional. 2015.

HASSE, D.. Garantia constitucional do acesso à justiça e a efetividade da tutela jurisdicional. 2013.

LIMA, D. L. C.. Teoria do valor do Desestímulo. 2009.

MACEDO, J.. Interrupções no serviço de telefonia móvel são cada vez mais frequentes. 2015.

MENDES, R. S.. A morosidade processual frente os direitos fundamentais e a ineficiência da Administração Pública. 2012.

MIRAGEM, B.. Curso de Direito do Consumidor. 2 ed. São Paulo: Revista dos Tribunais, 2016.

NUNES, L. A. R.. Curso de Direito do Consumidor. 12 ed. São Paulo: Saraiva Educação, 2018.

SINDEC. Assuntos mais reclamados e Empresas mais reclamadas. SINDEC, 2019.

TARTUCE, F.. Manual de Direito Civil: volume único I. 6 ed. Rio de Janeiro: Forense; São Paulo: Método, 2016.

TEÓFILO, S.. Com 77,1 milhões de processos em tramitação, CNJ aponta queda do número de 2018 para 2019, houve uma redução de 1,5 milhão de processos sem solução no judiciário brasileiro. 2020.

A CBPC - Companhia Brasileira de Produção Científica (CNPJ: 11.221.422/0001-03) detém os direitos materiais desta publicação. Os direitos referem-se à publicação do trabalho em qualquer parte do mundo, incluindo os direitos às renovações, expansões e disseminações da contribuição, bem como outros direitos subsidiários. Todos os trabalhos publicados eletronicamente poderão posteriormente ser publicados em coletâneas impressas sob coordenação da Sustenere Publishing, da Companhia Brasileira de Produção Científica e seus parceiros autorizados. Os (as) autores (as) preservam os direitos autorais, mas não têm permissão para a publicação da contribuição em outro meio, impresso ou digital, em português ou em tradução. 